\title{
Região de fronteira terrestre Brasil-Argentina: uma contribuição ao debate sobre desenvolvimento regional
}

Rosa de Barros Ferreira de Almeida*

\begin{abstract}
Resumo
O objetivo desse artigo é dar uma contribuição ao debate sobre desenvolvimento regional, a partir de um estudo de caso sobre a região da fronteira Brasil-Argentina. Para alcançar esse objetivo, recorre a referências bibliográficas que tratam desse assunto. Realiza-se pesquisa descritiva de abordagem qualitativa. A região de fronteira de Santa Catarina com a Argentina conta com 82 municípios e cerca de 900 mil habitantes. O governo do estado de Santa Catarina criou, seguindo determinação do governo federal, o Núcleo Estadual da Região da Faixa de Fronteira. As ações desenvolvidas até o momento estão voltadas em melhorar a infraestrutura fronteiriça, sistema de segurança, estrutura educacional, sistema de saúde, desenvolvimento do turismo e da agricultura. Citam-se algumas ações realizadas, como melhoria na alfandega para transito de pessoas e veículos, sistema de informações voltada à segurança, atendimento médico-hospitalar, implantação de sistema bilíngue na educação, cooperação técnica entre entidade de pesquisa e extensão agropecuária, entre outros.
\end{abstract}

Palavras-chave: Desenvolvimento econômico; instituições; Free Shop de fronteira terrestre.

\section{Brasil-Argentina land border region: a contribution to the debate on regional development}

\begin{abstract}
The aim of this articles is to contribute to the discussion on regional development, based on a case study on the Brazil-Argentina border region. To achieve this goal, it uses bibliographical references that deal with this subject. Descriptive research with a qualitative approach is carried out. The border region between Santa Catarina and Argentina has 82 municipalities and around 900 thousand inhabitants. The government of the state of Santa Catarina, created, following determination of the federal government, the State Center for the Border Strip Region. The actions developed so far are aimed at improving the border infrastructure, security system, educational structure, health system, tourism and agriculture development. Some actions carried out are mentioned, such as improving customs for the transit of people and vehicles, information system focused on safety, medical and hospital care, implementation of a bilingual education system, among other.
\end{abstract}

Keywords: Economic development; institutions; Free Shop, land border.

Classificação JEL: R00; R1; R11

\footnotetext{
* Doutoranda em Administração no Programa de Pós-Graduação em Administração da Universidade Federal de Santa Catarina, Mestre em Estudos Fronteiriços pela Universidade Federal de Mato Grosso do Sul e Professora do Curso de Administração na Universidade Federal de Mato Grosso do Sul, Campus do Pantanal. E-mail: rosaalmeida1527@gmail.com
} 


\section{Introdução}

Conforme Lei Federal $\mathrm{n}^{\mathrm{o}}$ 6.634/1979, regulamentada pelo Decreto $\mathrm{n}^{\mathrm{o}}$ 85.064, de 26/08/1980 a Faixa de Fronteira abrange uma área de cento e cinquenta quilômetros de largura, situada ao longo dos $15.719 \mathrm{~km}$ de fronteira do território nacional. Nessa faixa, os municípios que fazem divisa com os países vizinhos são classificados como de "linha de fronteira", enquanto que as cidades que possuem ligação direta com um ou mais vizinhos são chamadas de "Cidades Gêmeas".

Cidades gêmeas são espaços localizados dentro da faixa de fronteira, onde se realizam as relações transfronteiriças. As cidades-gêmeas brasileiras estão localizadas no Rio Grande do Sul, Mato Grosso do Sul, Acre, Paraná, Santa Catarina, Roraima, Amapá, Rondônia e Amazonas. O Brasil compartilha o reconhecimento com a Argentina, Paraguai, Guiana Francesa e Uruguai. Através da publicação da lista das chamadas cidades-gêmeas brasileiras pelo Ministério da Integração esperava-se que o reconhecimento destas cidades-gêmeas fosse um primeiro passo para a formulação de políticas públicas conjuntas, para tratar de problemas e de oportunidades comuns aos dois lados da fronteira (BRASIL, 2014).

No considerado arco Sul, encontra-se região de fronteira composta por três países: Paraguai, Argentina e Uruguai, totalizando $3.694 \mathrm{~km}$ de extensão. Considerando a faixa de fronteira de $150 \mathrm{~km}$ de largura, encontram-se 418 municípios brasileiros, assim distribuídos: 139 no Paraná, 82 em Santa Catariana e 197 no Rio Grande do Sul. (PÊGO, B. et al., 2020, p. 151). Dos 33 municípios contemplados como cidades-gêmeas, 16 estão localizados nessa região sul do Brasil, a saber: onze (11) no estado do Rio Grande do Sul; quatro (4) no estado do Paraná e um (1) no Estado de Santa Catarina.

A integração da área de fronteira é uma diretriz do Programa de Promoção do Desenvolvimento da Faixa de Fronteira (PDFF), que tem por objetivo incorporar essas porções do território à dinâmica econômica nacional e, também, às regiões vizinhas. Para isso, enfatiza o desenvolvimento das cidades gêmeas, a dinamização dos arranjos produtivos e o fortalecimento dos atores que atuam nesse território (BRASIL/MI, 2009). O desenvolvimento considerando a integração nacional tendo como panorama a preocupação com o equilíbrio do desenvolvimento territorial e a argumentação em favor de um posicionamento mais decisivo do Estado diante de problemas resultantes do funcionamento do sistema econômico. Tal espaço territorial deve ser inserido como integrante do desenvolvimento, e não colocado à margem do processo de desenvolvimento (CARGNIN, 2014). 
Nesse contexto, este estudo tem como objetivo contribuir para o tema de desenvolvimento regional, apontando ações e aspectos da realidade existente na região fronteiriça com a Argentina. Nessa região existem 82 municípios e tem o Dionísio Cerqueira como cidade-gêmea. Para tanto, o mesmo foi estruturado em seis seções. Nessa $1^{\text {a }}$. seção encontra-se a introdução; na $2^{\mathrm{a}}$. seção realiza-se discussão teórica analítica, com foco no desenvolvimento econômico e desenvolvimento regional; na $3^{\mathrm{a}}$. seção apresenta-se a metodologia; na $4^{\mathrm{a}}$. seção, discute-se aspectos da região fronteiriça brasileira; na $5^{\mathrm{a}}$. seção apontam-se realizações presentes na região fronteiriça Brasil-Argentina, sob perspectiva de ações promovida por atores de Santa Catarina; e, por fim, na $6^{a}$. seção, traçam-se as considerações finais.

\section{Desenvolvimento econômico e desenvolvimento regional: notas teóricas analíticas}

O desenvolvimento econômico, conforme Bresser Pereira (2006), consiste em um processo histórico de acumulação de capital e de aumento da produtividade por que passa a economia de um país objetivando a melhoria dos padrões de vida de sua população. Esse processo histórico se desenvolve a partir da composição de cenários econômico-social, com a Revolução Capitalista; político, com a formação dos modernos estados-nação, e cultural caracterizado pela transição para a modernidade.

Considera Bresser Pereira (2006), que a maior ou menor aceleração do desenvolvimento capitalista é determinada inicialmente pela existência ou não de uma estratégia nacional de desenvolvimento, e, depois pela qualidade dessa estratégia — da coesão da nação e do acerto das instituições criadas e das políticas adotadas. Afirma que o Estado é forte quando tem legitimidade política e capacidade para cobrar impostos e impor a lei.

Para Bresser Pereira (2006) decorre daí que a teoria do desenvolvimento econômico é necessariamente uma teoria que deve explicar como as nações promovem o bem-estar de suas populações, usando como principal instrumento o próprio estado, e como instrumento complementar duas outras instituições: o mercado e o dinheiro. Assim, o desenvolvimento econômico é o resultado de uma estratégia nacional, que, em cada momento histórico, procura combinar escassos recursos disponíveis e instituições, motivando e orientando os agentes econômicos a investir e inovar.

Ressalta que na formulação de estratégias nacionais de desenvolvimento encontrar o equilíbrio na tensão social desses agentes econômicos é o grande desafio, já que estão em 
permanente conflito, embora a cooperação entre eles seja também essencial para o desenvolvimento do país. Nestes termos, uma estratégia nacional de desenvolvimento é uma instituição fundamental de um estado-nação porque estabelece pautas para a ação de empresários, de trabalhadores, das classes médias profissionais, e, dentro desta, da própria burocracia do estado. Embora as estratégias de desenvolvimento compartilhem características comuns não significa que o desenvolvimento seja um processo linear e harmônico. Pelo contrário, ele é caracterizado por rupturas importantes, tecnológicas e políticas, sendo marcado por tensões ou contradições fundamentais.

Corroborando com esse entendimento, Lima e Simões (2010) afirmam que o processo de desenvolvimento econômico não ocorre de maneira igual e simultânea em toda a parte. Pelo contrário, trata-se de um processo bastante irregular e uma vez iniciado em determinados pontos possui a característica de fortalecer áreas mais dinâmicas e que apresentam maior potencial de crescimento.

Nesse contexto, o Estado, enquanto instituição, tem um papel crucial entre os fatores condicionantes das realidades econômicas, políticas e sociais, sendo responsável por definir e cuidar das regras e da base legal de uma sociedade, estando relacionado aos direitos sobre propriedade e regras de produção, formalizando as instituições. Na América Latina o paradigma da Comissão Econômica para América Latina e Caribe (CEPAL) e o do Consenso de Washington foram os dois principais paradigmas de política econômica dos últimos 50 anos. Para Iglesias (2010) há como se aproveitar das boas e más lições deixadas pelo papel do Estado nos dois paradigmas e a partir dessas experiências, identificar alguns objetivos relevantes na busca de um novo Estado.

Corroborando para a compreensão do papel do Estado para favorecer o desenvolvimento, Boyer (1999) afirma que na origem da economia política já se encontrava o problema do desenvolvimento e a questão do papel específico do Estado e do mercado nesse processo complexo. Entre esses dois extremos, antigos e novos keynesianos, insistem no fato que o mercado produz desequilíbrios na acumulação, no crédito e no mercado de trabalho. A esfera do mercado não deveria ser nem muito grande nem muito reduzida, em oposição às visões tanto neoclássicas quanto estruturalistas.

Segundo Boyer (1999) por um lado, os teóricos, mesmo os liberais, e os organismos internacionais, reconheceram que o Estado tinha uma responsabilidade essencial na construção das instituições necessárias ao florescimento do mercado e do espírito de empresa. Por outro lado, as teorias que exploram as consequências da assimetria da informação concluem em geral pelo caráter subótimo de um equilíbrio de mercado, ocorrem então racionamentos nos mercados 
de trabalho e de crédito, de modo que intervenções corretivas são capazes de melhorar a situação de todos os agentes econômicos. O Estado tem assim, por função, corrigir as falhas do mercado.

Porém, existe outra parte da literatura que se aplica mais diretamente ao desenvolvimento: a teoria do progresso técnico endógeno, que enfatiza o papel das externalidades positivas associadas à inovação, ao capital humano formado no interior do sistema educacional ou da empresa. De fato, para as teorias modernas, o Estado reencontra um papel próprio, que o mercado não poderia preencher. Não somente corrige as lacunas do mercado, mas institui vários deles, graças à promulgação de regras precisas que garantem a viabilidade, com base no modelo de mercados financeiros modernos (BOYER, 1999).

Deste modo, conforme Stiglitz citado por Boyer (1999) para os teóricos neokeynesianos, os poderes públicos têm por função corrigir as imperfeições do mercado. Para os novos institucionalistas, a ordem política tem um papel criador em matéria de incentivos econômicos. Da análise comparativa do desenvolvimento e da teoria econômica moderna, pode-se concluir que uma das condições para o desenvolvimento está no equilíbrio das relações entre Estado e mercado, pois nenhuma estratégia pura, seja baseada no "só Estado", seja no "só mercado" teve êxito.

A solução é compensar as falhas do mercado por meio de intervenções públicas adequadas e, vice-versa, o sucesso do desenvolvimento se deve à complementaridade dessas duas lógicas e não à afirmação de uma delas. Nesse sentido, os ordenamentos institucionais intermediários entre o Estado e o mercado, tais como a associações, as comunidades, as parcerias, podem ter um papel determinante na conciliação dos imperativos de eficiência dinâmica (BOYER, 1999).

Nesse contexto, para Sanchez (2018), o papel do Estado de articulador é complexo, pois envolve muitos atores, cada qual com seus interesses diversos e com recursos diferenciados, de modo que grande parte das chances de sucesso do planejamento dependerá da capacidade do Estado de articulação nos diversos níveis.

De acordo com Bellingeri (2017) as Teorias do Desenvolvimento Regional foram inspiradas na Teoria Keynesiana, especificamente na análise macroeconômica, e trazem como elemento comum a existência de uma atividade econômica que lidera com dinamismo e propagando seus efeitos aos demais setores da economia, gerando assim o crescimento. Tratase do paradigma de cima para baixo, ou "centro-abaixo", baseado numa força externa, exógena, que se instala na região e dá origem ao desenvolvimento. 
Na mesma direção, Oliveira e Lima (2003) afirmam que as teorias clássicas a respeito do desenvolvimento regional, geralmente, denotam a ideia da existência de uma força motriz de caráter exógeno capaz de influenciar, por meio de encadeamentos (linkages effects), as demais atividades econômicas. Em linhas gerais, é o conhecido paradigma "centro-abaixo" devido à presença de forças impulsoras advindas das regiões centrais. Segundo esses autores, esta definição abarca a Teoria da Base de Exportação, a Teoria da Difusão e a Teoria do Polo de Crescimento.

A Teoria da Base de Exportação considera as exportações como a principal força desencadeadora do processo de desenvolvimento, o crescimento é dependente da dinamicidade das atividades econômicas básicas, essas por sua vez, são incentivadoras do desenvolvimento de atividades complementares. Na Teoria da Difusão, o desenvolvimento ocorre com a industrialização e com a concentração das atividades em um número reduzido de grandes centros urbanos que irradiam seus efeitos/encadeamentos, sendo capazes de dinamizar a economia das demais regiões. (OLIVEIRA; LIMA, 2003).

Esses autores destacam ainda que a ideia de força motriz também está presente no trabalho de François Perroux, que desenvolve em sua obra a Teoria dos Polos de Crescimento. Essa teoria considera que a inserção de uma atividade motriz, geralmente indústria, dentro de um sistema regional é capaz de gerar efeitos positivos e negativos para a região receptora. Conforme esses efeitos vão se concentrando, a atividade motriz se torna um polo propulsor da economia da região. Desta forma, o desenvolvimento dependerá do nível e da qualidade dos efeitos gerados: positivos e negativos.

Oliveira e Lima (2003) consideram que todas as teorias tradicionais que fazem parte do paradigma "centro-abaixo", servindo de suporte às políticas econômicas, valorizam demasiadamente uma força externa (exógena) e excluem setores fundamentais, particularmente, da sociedade local, e em geral, da sociedade civil. Desta forma, os autores identificam nas entrelinhas das teorias tradicionais a presença da visão dos primeiros europeus, de que as populações locais não têm nada a dizer ou a ensinar, devendo ser apenas “catequizadas", como foram os nativos americanos no início das grandes navegações.

Em suas palavras "pensar em desenvolvimento regional é, antes de qualquer coisa, pensar na participação da sociedade local no planejamento contínuo da ocupação do espaço e na distribuição dos frutos do processo de crescimento" (OLIVEIRA; LIMA, 2003, p. 31). É nesse contexto que procuram analisar o desenvolvimento regional a partir de uma perspectiva endógena, com ênfase nos fatores internos à região, sendo capazes de transformar um impulso externo de crescimento econômico em desenvolvimento para toda sociedade. 
É o chamado paradigma "desde baixo", em que há uma inversão de perspectiva, ao valorizar os fatores internos ou endógenos, este paradigma aponta a necessidade das políticas macroeconômicas privilegiarem os elementos locais para promoção do desenvolvimento, visando aproveitar plenamente os recursos humanos, ambientais e institucionais da região. Nas palavras de Vázquez Barquero (2001, p. 181): No decorrer das últimas décadas (...), vem ganhando ímpeto a abordagem conhecida como de "baixo para cima", formada por políticas propostas e administradas pelos governos locais e regionais e que procuram assegurar o desenvolvimento econômico de cidades e regiões.

Em consonância com esse paradigma "desde baixo", Vázquez Barquero (2001) reconhece que a teoria do desenvolvimento endógeno concebe o desenvolvimento dentro de um cenário estratégico, no qual a capacidade de auto-organização permite ao território responder, de maneira diferenciada, às necessidades que lhes são colocadas pelo entorno econômico e social de acordo com as estratégias dos diversos agentes, econômicos, sociais e institucionais, da comunidade local.

Para Vázquez Barquero (2001, p. 39) "o território é um agente de transformação e não mero suporte dos recursos e das atividades econômicas, uma vez que há interação entre as empresas e os demais atores, que se organizam para desenvolver a economia e a sociedade". Deste modo, o território deixa de ser meramente o palco onde se desenrolam as atividades econômicas, para ser o protagonista da geração do desenvolvimento. Contudo, conforme ressaltam Filippim et al (2012) é importante considerar que se tratando de políticas públicas pelo desenvolvimento regional para territórios de fronteiras, a mobilização territorial em torno do desenvolvimento requer uma governança do tipo multinível, com complexa coordenação de múltiplos atores institucionais e de diversas esferas de governo.

Nessa linha da importância da governança pública, Dias e Cario (2017, p. 189) apontam que constitui um movimento que surge a partir das últimas décadas do século $\mathrm{XX}$, denotando para mudança do padrão de gestão centralizado, "em direção a outro que elege a participação da sociedade na elaboração das políticas, na realização de tarefas, no acompanhamento de resultados, na melhoria dos serviços públicos e atos que expressam maior relação integradora, Estado e sociedade".

Nesse contexto, aborda-se a questão do desenvolvimento endógeno, porque ele é capaz de viabilizar uma resposta local aos desafios da globalização sendo na visão de Vázquez Barquero (2001, p. 29) "um instrumento para a ação". Ademais, no Brasil, o prestígio do desenvolvimento endógeno segundo Bellingiere (2017, p. 76), “abriu caminho para uma série 
de políticas, estratégias e experiências práticas voltadas à promoção do desenvolvimento, em regiões e cidades".

\section{Aspectos metodológicos}

A pesquisa se caracteriza como uma pesquisa descritiva, uma vez que busca descrever a realidade do Estado de Santa Catarina em relação ao desenvolvimento econômico regional que se processa na região de fronteira com a Argentina. Trata-se também de um estudo exploratório, visto que está sendo vinculado às temáticas: desenvolvimento econômico, desenvolvimento regional e ações de Estado, nacional e federativo em prol da sociedade.

No tocante a abordagem de pesquisa, esta, se classifica como uma pesquisa qualitativa. Em relação aos procedimentos técnicos utilizados, inicialmente foi realizada uma pesquisa bibliográfica, seguida pela pesquisa documental, para o levantamento dos avanços na regulamentação da Lei 12.723/2012 a partir dos documentos disponibilizados nos websites.

A escolha pelo estudo de caso único se justifica por ser este um fenômeno muito particular, embora em Santa Catarina apenas o município de Dionísio Cerqueira tenha sido caracterizado como cidade-gêmea, ele apresenta uma configuração de fronteiras que faz conviver cidadãos de dois países distintos (Brasil e Argentina), três municípios (Dionísio Cerqueira, Bernardo de Irigoyen e Barracão), dois Estados (Paraná e Santa Catarina) e uma província (Misiones).

\section{As fronteiras nacionais e o caso da fronteira sul}

$\mathrm{Na}$ atualidade, o Brasil mantém fronteira com dez países do subcontinente: Uruguai, Argentina, Paraguai, Bolívia, Peru, Colômbia, Venezuela, Guiana, Suriname e Guiana Francesa, com exceção apenas do Equador e Chile, envolvendo assim onze unidades federativas. A Faixa de Fronteira é resultado de um processo histórico baseado na preocupação do Estado, com a garantia da soberania territorial desde os tempos da Colônia. Embora a principal legislação em vigor sobre a Faixa de Fronteira tenha sido promulgada em 1979, o espaço territorial de segurança paralelo à linha de fronteira existe desde o Segundo Império. A faixa de fronteira de $150 \mathrm{~km}$ de largura, definida pela Lei $\mathrm{n}^{\circ}$ 6.634/1979, compõe-se de 588 municípios, abrangendo $27 \%$ do território nacional com $15.719 \mathrm{~km}$ de extensão (BRASIL, 2017). 
A faixa de fronteira brasileira se divide em três grandes arcos - $\mathrm{O}$ arco Norte compreende os estados de Acre, Amazonas, Roraima, Pará e Amapá; o arco Central, Rondônia, Mato Grosso e Mato Grosso do Sul; e o arco Sul, Paraná, Santa Catarina e Rio Grande do Sul (BRASIL, 2005), a Tabela 1 apresenta a distribuição de municípios em cada arco.

Tabela 1: Distribuição dos municípios por estado em cada um dos Arcos.

\begin{tabular}{|c|c|c|}
\hline ARCO & ESTADO & QUANTIDADE DE MUNICÍPIOS \\
\hline \multirow{6}{*}{ Norte } & Amapá & 8 \\
\hline & Pará & 5 \\
\hline & Roraima & 15 \\
\hline & Amazonas & 21 \\
\hline & Acre & 22 \\
\hline & Total & 71 \\
\hline \multirow{4}{*}{ Central } & Rondônia & 27 \\
\hline & Mato Grosso & 28 \\
\hline & Mato Grosso do Sul & 44 \\
\hline & Total & 99 \\
\hline \multirow{4}{*}{ Sul } & Paraná & 139 \\
\hline & Santa Catarina & 82 \\
\hline & Rio Grande do Sul & 197 \\
\hline & Total & 418 \\
\hline Total de Municipios & & 588 \\
\hline
\end{tabular}

Fonte: Brasil (2017).

A justificativa para o recorte territorial por arco apoia-se "na necessidade de dimensionar os recortes da faixa de fronteira do país, ao buscar um entendimento detalhado dos aspectos sociais e econômicos e considerar a importância estratégica dos munícipios de fronteira" (BRASIL, MDR, 2020, p. 30). A macro divisão em três grandes arcos, conforme a Figura 1 foi adotada pelo Programa de Desenvolvimento da Faixa de Fronteira (PDFF) para fins de análise e planejamento. O PDFF "tem como objetivo principal promover o desenvolvimento da Faixa de Fronteira por meio de sua estruturação física, social e produtiva, com ênfase na ativação das potencialidades locais e na articulação com outros países da América do Sul". Logo, busca-se através a implementação de iniciativas que considerem a diversidade da região em consonância com as diretrizes da Política Nacional de Desenvolvimento Regional (PNDR).

A PNDR foi concebida pelo Ministério da Integração Nacional com a finalidade de institucionalizar mecanismos e instrumentos imprescindíveis para a consolidação de conceitos como inserção social e econômica, valorização do potencial endógeno ou "desenvolvimento regional", conceitos estes que têm se concretizado no país nos últimos anos, dada sua relevância. Pois o desenvolvimento regional "é fator decisivo para o fortalecimento das 
políticas públicas voltadas para a potencialização e recuperação da população a partir de uma força centrífuga, ou seja, de dentro para fora" (BRASIL, 2017, p.9). A singularidade desta forma de política reside em sua abordagem, já que busca dinamizar a economia, fornecer infraestrutura adequada de logística, promover melhorias sociais e de cidadania, ao fortalecer os atores e preservar as particularidades locais.

Figura 1: Arcos da faixa de fronteira do Brasil

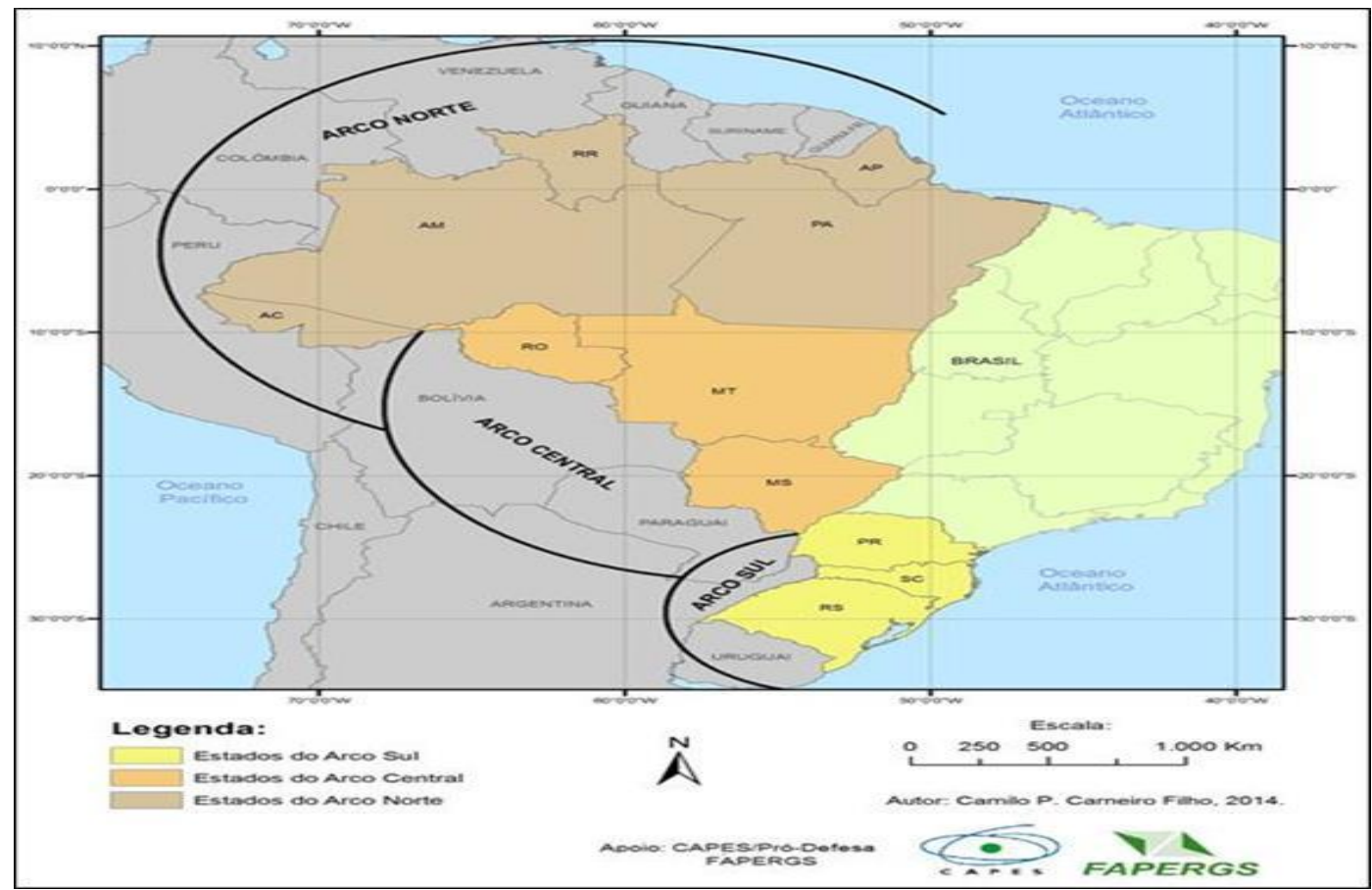

Fonte: Carneiro P. Carneiro Filho/ V Seminário Estudos Fronteiriços, 2015.

Desta forma, as políticas públicas e estratégias de desenvolvimento devem ser redefinidas e adequadas a essa realidade regional diversificada. Por essa razão, o livro "Fronteiras do Brasil: referências para a formulação de políticas públicas (volume 6)" - IPEA (2021) tem como objetivo subsidiar a formulação de políticas públicas (planos, programas e ações) visando ao desenvolvimento e à integração do espaço fronteiriço e será adotado como base para descrever as particularidades de cada arco nos próximos parágrafos.

No arco Norte, a diversidade da fronteira é demarcada pela presença de reservas naturais e florestas, devido à potencialidade de riquezas minerais e biodiversidade da Amazônia, ela torna-se uma prioridade, sendo também relevante pelo número de terras indígenas (TIs). Povoada por indígenas, populações remanescentes de quilombos, ribeirinhos, pescadores artesanais, carvoeiros, seringueiros, castanheiros, coletores de açaí, entre outros povos tradicionais, a dimensão da Amazônia e sua baixa densidade demográfica, quando comparada 
com outras regiões, é o seu maior desafio. Logo, “qualquer ação no arco Norte deve se reportar aos diversos agentes, atores e arranjos produtivos peculiares, como uma forma de aprimorar os diferentes projetos territoriais na construção de alternativas de desenvolvimento para a população" (PÊGO et al., 2017; 2018 apud BRASIL, 2021, p. 53).

No arco Central, por sua vez, há um reconhecimento de que a zona de fronteira é um espaço de interações, contatos e fluxos sociais, econômicos e culturais, movido por semelhanças e contrastes, onde se estabelecem arranjos transfronteiriços com fortes vínculos e relações familiares, profissionais, comerciais e institucionais que superam a linha divisória territorial. Consequentemente, surge a necessidade de uma aproximação institucional e, aprofundamento no relacionamento entre o governo do município brasileiro e o governo da cidade do país vizinho. Em razão das grandes porções de limite seco, onde não há obstáculos físicos significativos de separação, os contatos de aproximação entre os países em vários pontos da fronteira do arco Central são facilitados, destaca-se que são contatos que vem se consolidando ao longo de alguns séculos, especialmente nas relações de parentescos, responsáveis pelo maior entrelaçamento cultural dos povos. Através do comércio em ambos os lados do limite fronteiriço, a movimentação da economia tem fortalecido essas relações.

O arco Sul é o mais dinâmico economicamente devido ao número de arranjos transfronteiriços que engloba, compreendendo a porção da faixa de fronteira com a maior densidade de população, dos 588 municípios que compõem a faixa de fronteira brasileira, 418 fazem parte desse arco, o que lhe confere uma densidade institucional muito grande, justificando sua relevância para seleção como foco desse trabalho. $\mathrm{O}$ arco sul possui uma rede urbana muito ramificada e fluxos de produção e comércio elevados, que são favorecidos por uma malha viária que garante possibilidades de conexão entre os países do Cone Sul, com os quais realiza intensas trocas, totalizando, no conjunto dos três estados sulinos (Paraná, Santa Catarina e Rio Grande do Sul), dezessete arranjos, com alguns envolvendo mais de uma Unidade da Federação (UF) e outros abrangendo mais de dois países (PÊGO, B. et al., 2020).

A respeito das concepções sobre o sentido da fronteira identificadas pela pesquisa do IPEA (2016) no arco Sul, de modo geral, há um reconhecimento de que as fronteiras não são uniformes, logo, uma única política torna-se incapaz de compreender a complexidade das redes construídas nessas regiões. Por conseguinte, se uma política pública pensada para todo o território, marcado por um conjunto de desigualdades, for executada da mesma maneira pode resultar em efeitos diversificados em cada lugar. Levando-se em conta a peculiaridade que cada fronteira possui e a influência de outra cultura, outra instituição organizacional sobre o espaço fronteiriço pode acontecer um embate entre as políticas existentes em cada lado. Assim, 
apreende-se que, para estabelecer o futuro da fronteira, políticas federais ou políticas centrais não são suficientes, sendo necessárias políticas locais, que tratam do cotidiano, das funções públicas, das dificuldades de cruzar a fronteira.

Embora ao se tratar das fronteiras a tendência seja expor somente elementos como problemas, dificuldades e pontos negativos que desmotivam o morador fronteiriço, afastam investidores e demarcam a ausência do Estado, são muitas as potencialidades e as oportunidades da região, um exemplo é a forma utilizada pela população fronteiriça para superar as dificuldades impostas pelas oscilações cambiais. Outro diferencial que deve ser potencializado é a localização geográfica das cidades da fronteira, em um curto intervalo de tempo, há a possibilidade de percorrer de dois a três países, conhecer suas riquezas, que são ímpares. Ademais, a educação também é percebida como uma oportunidade, ainda que com dificuldade de acesso a ela, evidenciou-se o efeito transformador no desempenho político e econômico de cidades como Sant'Ana do Livramento e Jaguarão, pela presença de universidades federais.

Quanto às principais dificuldades enfrentadas pelo morador fronteiriço, destacam-se: a oscilação cambial, que na crise, faz as famílias migrarem para grandes centros, empresas comerciais encerrarem suas atividades, aumentando o número de imóveis fechados e postos à venda. Em consequência, a tendência da evolução da população no arco Sul torna-se preocupante, devido à diminuição do crescimento populacional, sobretudo nas áreas rurais. "Sant'Ana do Livramento e Uruguaiana, grandes municípios desse arco da fronteira, perderam efetivamente população na década passada, e muitos municípios repetem esse desempenho de perda ou vêm crescendo a taxas muito reduzidas" (PÊGO, B. et al., 2020, p. 307).

Há ainda dificuldades quanto ao alinhamento das ações com os países vizinhos, deparando-se com aspectos como a diferença linguística, territorial, de acessos, de documentação e de validação de títulos, que apesar de reivindicados seguem sem soluções que favoreçam a interação existente. São mencionadas também as diferenças de legislação, que impõem limites à preservação ambiental e a prática da pesca, além de favorecer o contrabando de agrotóxicos etc. Neste contexto, de acordo com o Pêgo, et al. (2020) a maior dificuldade da região de fronteira é o combate aos ilícitos, oriundo de outras escalas, desde a escala global voltada ao controle do mercado de armas e de tecnologias, até a transformação da fronteira em um lugar de conflito para ser realizar negócios.

Desta forma, no enfrentamento dos problemas fronteiriços uma série de desafios é elencada. O primeiro se refere ao fortalecimento de uma educação transfronteiriça com finalidade de estimular a cooperação e o entendimento entre os povos, em favor de uma cultura, história e costumes comuns, em convivência. É essencial o acesso “à educação, o aprendizado 
da língua espanhola nas escolas brasileiras e do português nas argentinas, uruguaias e paraguaias, e a existência de documentos comuns aos dois ou três países, fazendo valer direitos comuns de cidadania aos povos transfronteiriços" (PÊGO, B. et al., 2020, p. 309). Incrementar a base econômica, no intuito de garantir determinado nível de renda à população dos países fronteiriços, bem como a dotação de infraestruturas que incrementem as possibilidades de atrair novos investimentos à região são outras tarefas desafiadoras.

Nas cidades fronteiriças, especialmente aquelas que configuram 'arranjos transfronteiriços', o atendimento a direitos sociais muitas vezes são postos 'no vácuo do espaço transfronteiriço' tornando a gestão de funções públicas de interesse comum desafiadora. No transporte público, por exemplo, os ônibus não podem cruzar a fronteira para a outra cidade, mesmo que estejam espacialmente interligadas; na saúde, o atendimento fica à mercê de uma portaria ministerial, que deveria ser específica para os hospitais em região de fronteira.

Na década de 1990 foi criado o Mercado Comum do Sul (MERCOSUL), considerado como "a mais abrangente iniciativa de integração regional da América Latina, surgida no contexto da redemocratização e reaproximação entre os países da região ao final da década de 1980” (BRASIL, MRE 2021). Os membros fundadores do MERCOSUL são Brasil, Argentina, Paraguai e Uruguai, signatários do Tratado de Assunção, escolheram como estrutura institucional a intergovernamental, estabelecida por órgãos compostos por representantes dos poderes executivos dos Estados membros e por um sistema de tomada de decisão consensual.

Particularmente, no que diz respeito aos acordos internacionais, o Brasil possui acordos bilaterais com 5 países: Argentina, Uruguai, Paraguai, Venezuela e Bolívia. No caso do Brasil e da Argentina, considerando que os dois países são unidos por uma linha de fronteira que se prolonga por $1.261 \mathrm{~km}$, sendo $1.236 \mathrm{~km}$ por rios e $25 \mathrm{~km}$ por fronteira seca, a política de integração fronteiriça se destaca na agenda de cooperação bilateral. A mais elevada instância para tratar de temas de integração fronteiriça é a Comissão de Cooperação e Desenvolvimento Fronteiriço Brasil-Argentina (CODEFRO). Estabelecida em 2011, a Comissão tem como objetivo "servir de instância de deliberação de políticas binacionais para a fronteira e garantir o seguimento e o encaminhamento adequado de temas e demandas suscitados no âmbito dos comitês de integração fronteiriça Brasil-Argentina" (PÊGO, B. et al., 2020, p.323). Esses comitês se reúnem anualmente nas localidades fronteiriças dos dois países e, atualmente, existem três comitês de integração fronteiriça entre Brasil e Argentina, nas cidades de Foz do Iguaçu-Puerto Iguazú; Dionísio Cerqueira/Barracão-Bernardo de Irigoyen e Uruguaiana-Paso de los Libres (PÊGO, B. et al., 2020). 
Em 2016, entrou em vigor o Acordo Sobre Localidades Fronteiriças Vinculadas, um instrumento inovador no campo da integração fronteiriça, que tem impulsionado a política de integração entre esses dois países, exatamente por reconhecer a realidade particular das comunidades da área de fronteira e buscar viabilizar soluções integradas para os problemas enfrentados pelas populações locais. Aos cidadãos das localidades fronteiriças do Brasil e da Argentina, o acordo possibilita o direito de adquirir uma Carteira de Trânsito Vicinal Fronteiriço (TVF) que tem o propósito de facilitar a circulação vicinal e a concessão de vários benefícios nas áreas de residência, estudo, trabalho, saúde, comércio, entre outras. Realizar exercício de trabalho, ofício ou profissão na localidade fronteiriça do país vizinho, ter acesso ao ensino público do outro lado da fronteira, ter a facilitação do trânsito de veículos particulares de nacionais fronteiriços entre as localidades vinculadas são alguns dos benefícios que os cidadãos portadores da TVF passaram a usufruir.

A cooperação fronteiriça também é ponto importante das relações bilaterais entre Brasil e Uruguai, um dos principais parceiros do Brasil na América do Sul. A existência de vínculos históricos, políticos e humanos entre eles permite estabelecimento de confiança mútua, que permeia todos os aspectos dessa relação bilateral: "a cooperação entre os dois países é abrangente, perpassando os campos político, econômico, tecnológico, cultural e social" (BRASIL, MRE, 2021).

A aproximação bilateral com o Paraguai é prioritária para o Brasil e contribui para a estabilidade democrática e desenvolvimento econômico e social da região. Ambos os países são parceiros desde a criação do MERCOSUL, membros plenos e fundadores do bloco, unem os esforços na busca do realinhamento do bloco aos propósitos originais do Tratado de Assunção (democracia e direitos humanos), com foco na dinamização do mercado interno do bloco e no fortalecimento da agenda negociadora externa. Brasil e Paraguai compartilham 1.339 quilômetros de fronteira - a quarta maior extensão de fronteira dentre os limites brasileiros e tradicionalmente, o Brasil é o principal parceiro comercial do Paraguai (BRASIL, MRE, 2021).

Quanto à fronteira entre Brasil e Venezuela, de acordo com o Pêgo, B. et al (2021), por ser constituída por várias áreas de proteção ambiental e reservas indígenas, é uma região deficientemente povoada, formada por somente duas cidades: Pacaraima (Br) e Santa Elena de Uairén (Ar). O principal foro para tratar dos assuntos de desenvolvimento e integração na fronteira como saúde, educação, meio ambiente, turismo e assuntos indígenas é o Grupo de Trabalho sobre Desenvolvimento Fronteiriço, contudo, a última reunião ocorreu a mais de 10 anos, em junho de 2010 em Brasília. 
Com a Bolívia, o Brasil compartilha sua maior fronteira, que se estende por aproximadamente $3.423 \mathrm{~km}$, bem como a condição de país amazônico e platino. As relações do Brasil com a Bolívia são preferenciais, pois abrangem iniciativas em diversas áreas, como: cooperação energética, cooperação fronteiriça e combate a ilícitos transnacionais, além de articulação em foros regionais e globais. Dentre essas iniciativas, merece destaque a cooperação energética, por constituir-se como insumo para a política energética brasileira e fonte de renda para a Bolívia. Essa parceria consolidou-se em 1958, com a assinatura das "Notas Reversais de Roboré", que promoveram inicialmente o tema de aquisição de gás boliviano e da construção de um gasoduto. Em 1999, ocorreu efetivamente a implantação do Gasoduto Bolívia-Brasil, responsável por estreitar as relações bilaterais e criar novas oportunidades para a inserção econômica da Bolívia no MERCOSUL (BRASIL, MRE, 2021).

\subsection{A região de fronteira Brasil-Argentina: uma contribuição ao estudo do desenvolvimento regional}

Considerando que a faixa de fronteira brasileira foi dividida pelo PDFF, segundo as características produtivas e a organização social em três arcos: Arco Norte, Arco Central e Arco Sul, um recorte foi feito com foco no Arco Sul, o "mais influenciado pela dinâmica transfronteiriça, que se materializa no projeto de integração do Mercosul, abrangendo os estados do Paraná, Santa Catarina e Rio Grande do Sul” (AVELINE BERTÊ et al., 2017, p. 61). No estado do Paraná, 139 municípios estão situados na Faixa de Fronteira, e destes atualmente quatro se caracterizam como cidades-gêmeas. Já no estado do Rio Grande do Sul há 197 municípios localizados na Faixa de Fronteira, sendo que onze destes caracterizam-se como cidades-gêmeas com grande fluxo de pessoas e mercadorias. No estado de Santa Catarina, por sua vez, 82 municípios estão situados na Faixa de Fronteira (FALK, 2015).

Conforme Broppé (2019), encontram-se localizados na região de fronteira com a Argentina, 82 municípios representando $28 \%$ dos municípios catarinenses, com uma população estimada em 900 mil habitantes, participação de 13,6\% dos habitantes do Estado. A Figura 2 (mapa) apresenta uma visualização da região de fronteira Santa Catarina com a Argentina. Além disso, o município de Dionísio Cerqueira constitui a cidade-gêmea catarinense com o território argentino. O Quadro 1 aponta a lista de cidades-gêmeas brasileiras na região Sul do país.

De acordo com Falk (2015), em julho de 2011 foi criado no estado do Rio Grande do Sul o Núcleo Regional de Integração da Faixa de Fronteira, no intuito de se constituir um espaço 
de coordenação de políticas nas esferas federal, estadual e municipal, além de se tornar um espaço de diálogo com os governos dos países vizinhos. Em 2012, com o objetivo de formular estratégias e ações mais integradoras para esse território foi concluído o Plano de Desenvolvimento e Integração da Faixa de Fronteira do Rio Grande do Sul (PDIF/RS).

Figura 2: Mapa da região de fronteira catarinense

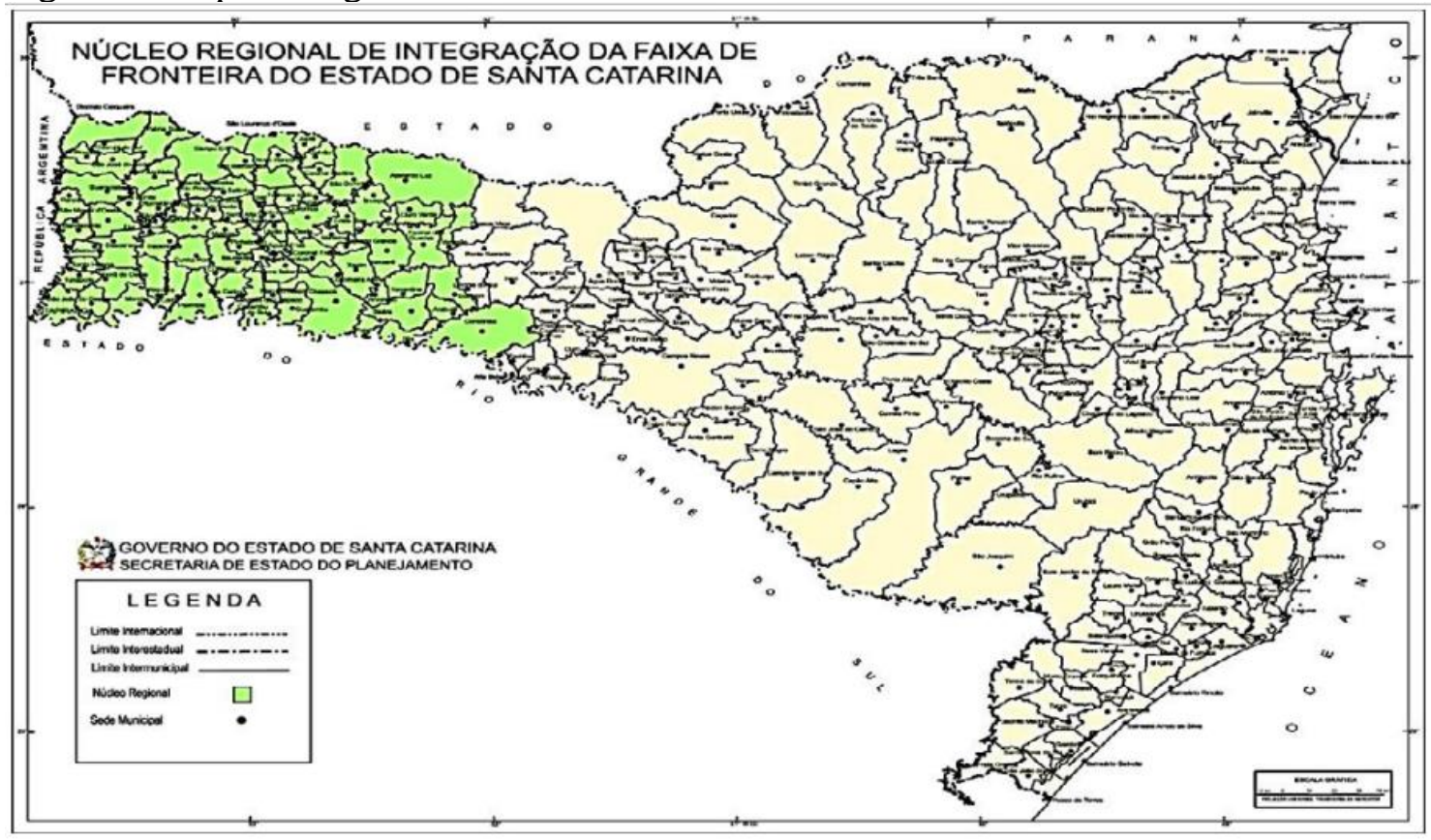

Fonte: SGP/DEGE (SANTA CATARINA, s.d., n.p) conforme Broppé (2019).

Os estados de Santa Catarina e Paraná também têm apresentado algumas iniciativas interessantes empreendidas por seus poderes públicos municipais. Com repercussão internacional, um dos destaques se deve ao inovador Consórcio Intermunicipal de Fronteira (CIF) firmado entre os municípios brasileiros de Barracão (PR), Bom Jesus do Sul (PR), Dionísio Cerqueira (SC), tendo como parceiro informal o município argentino de Bernardo de Irigoyen (Misiones/Ar). Antes de sua criação, uma série de políticas e recursos dos governos nacionais e estaduais não chegavam nestes municípios, dado o número de habitantes. Através da cooperação intermunicipal para resolver problemas comuns passaram a ser contemplados, pois puderam ter o número de habitantes contabilizados conjuntamente (FALK, 2015).

O modelo de desenvolvimento do estado contribui para a diferenciação da região da faixa de fronteira catarinense das demais regiões fronteiriças do País. Vários fatores cooperam para ocorrência dessa particularidade: a inexistência de grandes áreas com baixa densidade demográfica, o modelo agrícola baseado em pequenas propriedades rurais/agricultura familiar, a ocorrência arranjos produtivos locais direcionados por diferentes vocações, além de uma 
notável integração socioeconômica nos setores da agropecuária, agroindústria, madeira, móveis e metal mecânica (BOPPRÉ, 2019). Trata-se de um estado que possui "um tecido industrial robusto, diversificado e presente em várias regiões e também um setor primário que interage fortemente com a indústria”. (LINS, 2018, p.249).

Quadro 1: Lista das cidades-gêmeas brasileiras da Região Sul, Brasil

\begin{tabular}{|c|c|c|c|}
\hline Ord. & Município & Estado & População est. 2018 \\
\hline 1 & Barracão & Paraná & 9.735 \\
\hline 2 & Foz do Iguaçu & Paraná & 256.088 \\
\hline 3 & Guaíra & Paraná & 30.704 \\
\hline 4 & Santo Antônio do Sudoeste & Paraná & 18.893 \\
\hline 5 & Aceguá & Rio Grande do Sul & 4.394 \\
\hline 6 & Santana do Livramento & Rio Grande do Sul & 83.464 \\
\hline 7 & Barra do Quaraí & Rio Grande do Sul & 4.012 \\
\hline 8 & Chuí & Rio Grande do Sul & 5.917 \\
\hline 9 & Itaqui & Rio Grande do Sul & 38.519 \\
\hline 10 & Jaguarão & Rio Grande do Sul & 27.931 \\
\hline 11 & Porto de Mauá & Rio Grande do Sul & 2.557 \\
\hline 12 & Porto Xavier & Rio Grande do Sul & 10.558 \\
\hline 13 & Quaraí & Rio Grande do Sul & 23.02 \\
\hline 14 & São Borja & Rio Grande do Sul & 61.671 \\
\hline 15 & Uruguaiana & Rio Grande do Sul & 125.435 \\
\hline 16 & Dionízio Cerqueira & Santa Catarina & 14.811 \\
\hline
\end{tabular}

Fonte: IBGE, 2018; Portaria 213, de 19/07/2016. Elaboração da autora

Além disso, ganha destaque a coordenação pelo governo de Santa Catarina, através da Secretaria de Estado do Planejamento, do Núcleo Estadual da Região da Faixa de Fronteira (NFSC), responsável pela criação de nove câmaras temáticas, para atuação em diferentes áreas governamentais, o NFSC tem protagonizado a realização de debates, estudos e encaminhamentos pertinentes ao desenvolvimento e à integração dessa populosa região da faixa de fronteira catarinense, estimada em 900 mil habitantes (BOPPRÉ, 2019).

Ainda a respeito do processo de integração, destacada a atuação do NFSC, em parceria com órgãos setoriais do governo de Santa Catarina, municípios e entidades que representam a sociedade civil organizada visando estabelecer convênios de integração e de desenvolvimento 
com o governo da província argentina de Misiones. O Quadro 2 apresenta as principais ações desenvolvidas e em curso na região da faixa de fronteira catarinense sob a coordenação do NFSC.

Dentre essas ações, destacam-se os acordos de cooperação, especificamente o Consórcio Intermunicipal de Fronteira (CIF), que tem despertado interesse em outros ambientes fronteiriços do MERCOSUL, sobretudo, porque a rapidez observada entre a demonstração de interesse pela criação do consórcio e a efetivação da iniciativa, sugere a capacidade local de articulação política e interlocução produtiva envolvendo diferentes esferas da administração pública. Ademais, essa iniciativa reflete por parte das lideranças municipais o entendimento de que seus espaços de atuação administrativa e política compartilham problemas que uma vez equacionados, demandam ações conjuntas e cooperativas (LINS, 2018).

Quadro 2: Cronologia das atividades do NFSC

\begin{tabular}{|l|l|l|}
\hline \multicolumn{1}{|c|}{ Ano } & \multicolumn{1}{|c|}{ Evento } & \multicolumn{1}{c|}{ Objetivo } \\
\hline $\mathbf{2 0 1 3}$ & $\begin{array}{l}\text { Reunião Inaugural dos } \\
\text { trabalhos. }\end{array}$ & $\begin{array}{l}\text { Relatar as atividades desenvolvidas em cinco das ações } \\
\text { estratégicas definida no Plano de Desenvolvimento e } \\
\text { Integração Fronteiriço de Santa Catarina (PDIF/SC). }\end{array}$ \\
\hline $\mathbf{2 0 1 4}$ & Reunião de trabalho & $\begin{array}{l}\text { Coordenar ações e propor medidas para implementação de } \\
\text { Políticas públicas para a região fronteiriça catarinense }\end{array}$ \\
\hline $\mathbf{2 0 1 5}$ & Encontro de Integração & $\begin{array}{l}\text { Obter subsídios para a reedição do Convenio Marco de } \\
\text { Cooperação entre os estados de Santa Catarina e a Província } \\
\text { de Misiones. }\end{array}$ \\
\hline $\mathbf{2 0 1 7}$ & Reuniões Ordinárias & $\begin{array}{l}\text { Debater, estudar e articular ações destinadas à integração } \\
\text { transfronteiriça (SC - BR e Misiones/AR). }\end{array}$ \\
\hline Acordo de Cooperação & $\begin{array}{l}\text { Assinatura de convênios técnicos entre os governadores de } \\
\text { Santa Catarina e Misiones destinados à integração de ações } \\
\text { nas áreas de educação, saúde e segurança pública. }\end{array}$ \\
\hline
\end{tabular}

Fonte: Boppré (2019) adaptado pela autora

O Acordo de Cooperação firmado entre o Estado de Santa Catarina - República Federativa do Brasil e a Província de Misiones - Repúbllica Argentina, em 04/12/2017, defini em sua Cláusula quinta que as reuniões do Grupo de Trabalho dos Comitês de Integração Fronteiriça - CIFs Brasil-Argentina - devem ser periódicas e que a coordenação das reuniões e o local de funcionamento devem respeitar um critério de rodízio entre as partes. Como apontado por Bopré (2019), os debates foram conduzidos por meio de comissões temáticas, tais como facilitação fronteiriça, infraestrutura, comércio e turismo, cultura, educação e saúde. Em decorrência da pandemia da Covid-19, em 2020 não houve reuniões (BRASIL, 2020). 
Sendo assim, segundo o Relatório de Atividades da Comissão Permanente para o Desenvolvimento e a Integração da Faixa de Fronteira - 2019-2020 do Ministério do Desenvolvimento Regional, os consulados brasileiros no lado argentino da fronteira organizaram as reuniões de 2019 nos seguintes locais e datas: Uruguaiana-Paso de los Libres em 13/08, São Borja-Santo Tomé em 15/08, Foz do Iguaçu-Puerto Iguazú em 17/09 e Dionísio Cerqueira/Barracão-Bernardo de Irigoyen em 19/09. Essas reuniões contaram com a participação de representantes dos municípios da faixa de fronteira, de autoridades nacionais, estaduais e locais presentes na fronteira oeste e das Chancelarias dos dois países.

Quadro 3: Principais ações do NFSC para a integração transfronteiriça.

\begin{tabular}{|c|c|}
\hline Temas de Interesse & Principais Ações \\
\hline $\begin{array}{c}\text { Infraestrutura e Facilitação } \\
\text { Fronteiriça }\end{array}$ & $\begin{array}{l}\text { Efetivação da estrutura alfandegária necessária ao efetivo funcionamento dos } \\
\text { passos de fronteira: na ponte que liga os municípios de Paraíso (SC) e San } \\
\text { Pedro (AR), bem como em Dionísio Cerqueira (BR) e Bernardo de Irigoyen } \\
\text { (AR); Regulamentação e efetivação do livre trânsito de veículos e pessoas } \\
\text { entre os países do MERCOSUL; Implantação de transporte público } \\
\text { binacional entre as cidades "gêmeas" ou de fronteira; Apoio à formação e } \\
\text { estruturação de consórcios municipais na Faixa de Fronteira, etc.; }\end{array}$ \\
\hline Segurança & $\begin{array}{l}\text { Ratificação por parte do Brasil do acordo intitulado Sistema de Intercâmbio } \\
\text { de Informação de Segurança do MERCOSUL, Bolívia e Chile (SISME), } \\
\text { objetivando a luta contra todas as formas de delinquência organizada, assim } \\
\text { como a criação de mecanismos de assistência recíproca entre as forças de } \\
\text { segurança e policiais e demais órgãos correlatos dos países do Mercosul; } \\
\text { Maior controle nas fronteiras devido à fragilidade que possibilita a entrada } \\
\text { de armas e de drogas, o tráfico de mulheres e de crianças e a prostituição; } \\
\text { etc.; }\end{array}$ \\
\hline Saúde & $\begin{array}{l}\text { Desburocratização do atendimento médico-hospitalar entre os países } \\
\text { limítrofes e fortalecimento das instituições dessa área; e, estabelecimento de } \\
\text { mecanismos de cooperação para a prevenção e o controle conjunto de } \\
\text { enfermidades diversas, além do combate à dengue, à zica e à febre amarela. }\end{array}$ \\
\hline Educação e Cultura & $\begin{array}{l}\text { Busca da possibilidade de dupla titulação e sistema de acreditação entre as } \\
\text { Universidades do MERCOSUL; Preservação e valorização da cultura das } \\
\text { pequenas cidades como um fator de integração cultural do MERCOSUL; } \\
\text { Implantação na rede de ensino pública do ensino bilíngue (idiomas português } \\
\text { e espanhol) nas regiões de fronteira, etc.; }\end{array}$ \\
\hline Turismo & $\begin{array}{l}\text { Promoção do intercâmbio sociocultural e turístico, com divulgação e } \\
\text { comercialização de produtos e apresentação das potencialidades de Santa } \\
\text { Catarina e Misiones; e, Desburocratização entre as fronteiras, facilitando o } \\
\text { acesso dos turistas, melhorando o atendimento nas aduanas. }\end{array}$ \\
\hline Agricultura & $\begin{array}{l}\text { Busca de estímulo à cooperação técnica entre as entidades de pesquisa e } \\
\text { extensão agropecuária (Brasil e Argentina), como intercambio; Ampliação } \\
\text { do conhecimento da demanda de produtos e serviços do agronegócio dos } \\
\text { países fronteiriços (Santa Catarina/Misiones), etc. }\end{array}$ \\
\hline
\end{tabular}

Fonte: Adaptado de Boppré (2019).

Em Santa Catarina, apropriando-se da importância dos ordenamentos das instituições intermediárias como associações, comunidades e parcerias foi possível entender porque o Estado tem se caracterizado como heterogêneo, englobando diversificadas áreas de 
desenvolvimento. Coordenado pela Secretaria de Estado do Planejamento, o Núcleo Estadual da Região da Faixa de Fronteira (NFSC) tem concentrado esforços em busca do desenvolvimento e integração. Uma síntese das principais ações é apresentada no Quadro 3.

Assim, apoiando-se nos resultados positivos do Consórcio Intermunicipal de Fronteira (CIF), o Núcleo Estadual da Região da Faixa de Fronteira (NFSC) tem demonstrado que é possível fazer com que iniciativas locais, desde que bem articuladas politicamente, envolvendo diferentes esferas da administração pública, se tornem casos de sucesso na resolução de problemas complexos que perfazem a realidade das regiões fronteiriças. Assim como no caso da criação do Plano de Desenvolvimento e Integração da Faixa de Fronteira do Rio Grande do Sul (PDIF/RS), o que pode ser observado é que há uma preocupação crescente quanto à necessidade de adoção do paradigma "desde baixo" a fim de que políticas macroeconômicas privilegiarem os elementos locais para promoção do desenvolvimento.

Na região de fronteira com Argentina destaque para a "cidade-gêmea" - Dionísio Cerqueira/SC. Localiza-se estrategicamente no limite entre Paraná e Santa Catarina e na fronteira do Brasil com a Argentina, conforme Figura 3. Dionísio Cerqueira existe desde meados do século XIX. O município foi colonizado por italianos e alemães vindos das colônias gaúchas, pertencendo a Chapecó até 1953, quando se tornou município. Seu nome é uma homenagem ao general Dionísio Cerqueira, antigo ministro das Relações Exteriores e que demarcou a fronteira Br/Ar (SEBRAE, 2013).

Figura 3: Localização de Barracão, Bernardo de Irigoyen, Bom Jesus do Sul e Dionísio Cerqueira, membros do CIF.

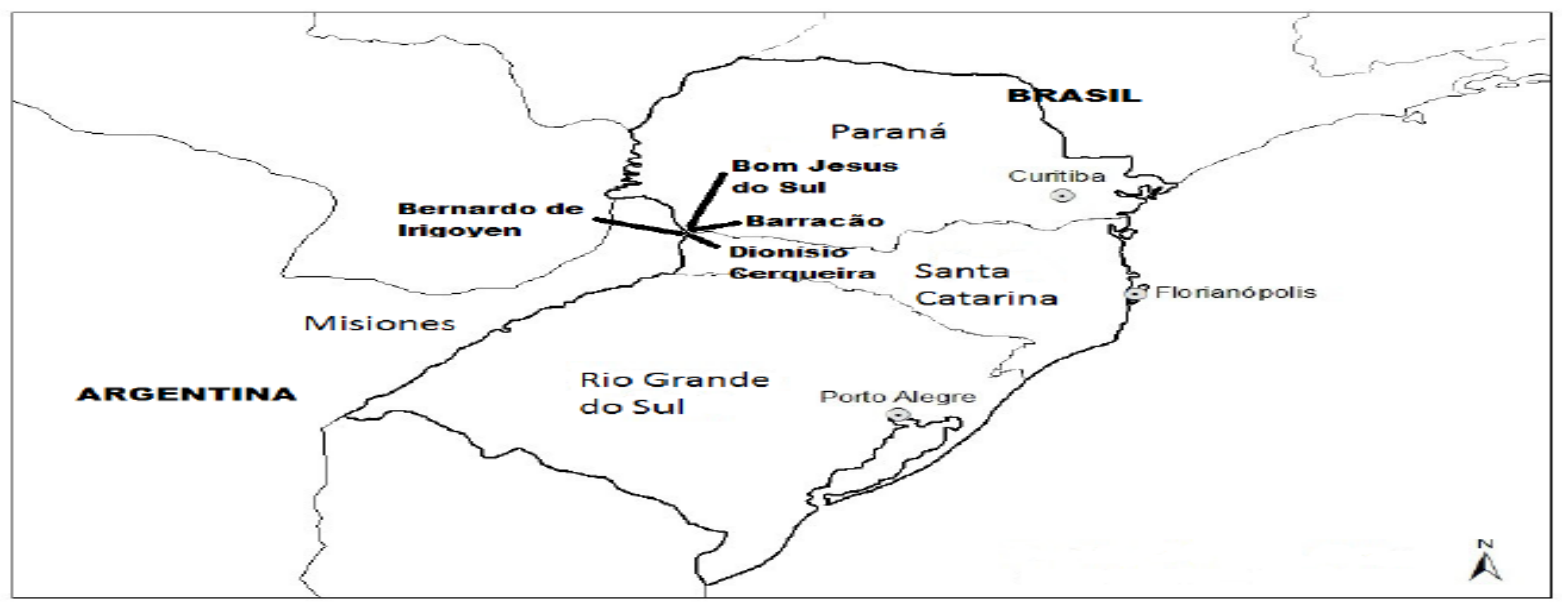

Fonte: Lins, 2018

Esse município apresenta um diferencial econômico voltado para o campo da exportação, possui em seu município um porto seco e duas aduanas; sua localização estratégica 
atraiu inúmeros investimentos e levou o Governo Federal a construir no município o único Porto Seco do MERCOSUL, o que o tornou a principal rota interoceânica entre as grandes metrópoles do Mercado Comum, refletindo como importante fator de atração em todo o território regional (LINS, 2012).

A implantação de free shops nesse município é vista como um possível mecanismo de desenvolvimento local e regional. Em 25/03/2015 foi publicada a Lei Ordinária nº 4.407/2015 autorizando, em caráter geral, a instalação de lojas francas em seu território. Para tanto, o Art $3^{\circ}$ dispõe sobre a constituição de um Grupo Técnico de trabalho que juntamente com as entidades empresarias deve trabalhar na elaboração de legislações municipais específicas para a regulamentação dos free shops no que diz respeito ao horário comercial de funcionamento, zoneamento das localidades favoráveis à instalação desses empreendimentos, bem como pela análise de projetos de grande porte que por ventura venham a surgir no processo de implantação. Contudo quando se busca normas relacionadas ao grupo técnico não há nenhuma outra informação.

A existência de lei municipal autorizando, em caráter geral, a instalação de lojas francas em seu território é um dos requisitos estabelecidos pela Portaria MI 307 de 17/07/2014. Considerando a peculiaridade do território, onde a configuração de fronteiras possibilita a convivência de cidadãos de dois países distintos, três municípios, dois estados e uma província, a efetivação de Free Shops, enquanto mecanismos de desenvolvimento local e regional, demanda extremo esforço. Talvez um dos maiores entraves seja a falta de pacto territorial entre os diversos agentes territoriais com a finalidade de propiciar uma construção social acerca de sua implantação, suas possibilidades e desafios.

O município de Dionísio Cerqueira, apto à implantação de free shop de fronteira, embora já disponha de lei municipal que a autorize, não há evidências de organização dos governos estadual e municipal, bem como agentes locais (empresários/ representantes da sociedade), quanto à efetiva implantação de Free-Shop. Mesmo sobre a constituição do grupo de trabalho, mencionada na Lei 4.470/2015, não se tem informação se de fato concretizou-se. É possível que uma das razões para esse cenário seja a ausência do elemento de governança pública coprodução do desenvolvimento regional por meio da cooperação entre Estado, mercado e sociedade civil, uma vez que, no Estado do Rio Grande do Sul, líder no país em número de lojas já instaladas, observa-se forte parceria/envolvimento/cooperação entre representantes destes três segmentos. 


\section{Considerações finais}

Santa Catarina possui uma região de fronteira com a Argentina, constituída por 82 municípios e cerca de 900 mil habitantes. Desses municípios, apenas um município figura na condição de cidade-gêmea, Dionísio Cerqueira. A área de fronteira insere-se na Política Nacional de Desenvolvimento Regional (PNDR), fazendo, portanto, parte da prioridade de desenvolvimento regional com presença do Estado, criando oportunidade de investimento e gerando melhores condições socioeconômicas para a população existente. Dentro desse Programa, encontra-se a Comissão Permanente para o Desenvolvimento e a Integração da Faixa de Fronteira que em linha com o Ministério, se responsabiliza pela área fronteiriça. Na época, o Ministério da Integração Nacional, definiu que os estados federativos criassem Núcleos Estaduais de Fronteira, com propósito de desenvolver programas de desenvolvimento e de integração fronteiriços.

Em linha com essa orientação, Santa Catarina, através da Secretaria de Estado do Planejamento - extinta no governo atual - criou o Núcleo Estadual da Região da Faixa de Fronteira. Esse núcleo tem atuado, pelas informações coletadas, de forma ativa criando câmeras temáticas de discussão; realizando estudos e debates; promovendo acordos de cooperação e convênios técnicos; desenvolvendo ações voltadas para as áreas de educação, saúde e segurança; e outros encaminhamentos de solução para problemas que cercam a região fronteiriça do estado com a Argentina.

Destaque para as algumas realizações efetuadas em prol do desenvolvimento da região. Algumas dessas ações podem ser citadas: na infraestrutura e facilitação fronteiriça melhoria no sistema alfandegário das pessoas e do trânsito de veículos; na área de segurança constituição de um sistema de informação de pessoas e combate a drogas e tráfico de pessoas; na saúde , desburocratização no atendimento médico-hospitalar de pessoas entre os países limítrofes; na educação e cultura, dupla titulação no sistema de ensino, implantação de sistema bilíngue e valorização da cultura local; no turismo, divulgação e comercialização de produtos turísticos e facilidade de acesso das pessoas; e na agricultura, cooperação técnica entre entidades de pesquisa e extensão agropecuária.

No estudo, evidenciou a possibilidade do município de Dionísio Cerqueira criar free shops, amparado por lei que permite tal empreendimento. Embora tenha criado a lei que autoriza a instalação, dispondo que seria formado um grupo de trabalho para tratar do processo de implantação desde a elaboração de legislações municipais específicas para a regulamentação dos free shops até a análise de projetos de grande porte, não foi encontrada nenhuma evidência 
de que o grupo foi efetivamente criado. Se criado ensejaria um maior envolvimento dos diversos atores do setor público e privado locais e regionais, e seria instrumentos de ação para promoção do desenvolvimento endógeno.

Provavelmente há a necessidade se fazer presente o elemento de governança pública coprodução do desenvolvimento regional por meio da cooperação entre Estado, mercado e sociedade civil, através de uma representação legítima da sociedade, abrindo caminhos para a efetiva implantação dos free shops de fronteira terrestre no município, a exemplo do que ocorre num círculo virtuoso no estado do Rio Grande do Sul, que conta com 11 já abertos e 5 em processo de abertura.

Por outro lado, conforme abordado no decorrer do trabalho, o município de Dionísio Cerqueira tem chamado atenção em relação a sua capacidade local de articulação política, no qual o elemento de governança pública faz-se presente. Isso pode ser observado com muita clareza quando se analisa, por exemplo, o caso do CIF e os resultados alcançados. Ademais, este município já possui através da criação do CIF reconhecida capacidade e experiência em auto-organização, o que lhe permite atender, com êxito, as necessidades que lhes são impostas por seu entorno econômico e social de acordo com as estratégias adotadas por seus diversos atores em estreita cooperação com os governos (municipal, estadual e nacional.

\section{Referências}

AVELINE BERTÊ, A. M.; CARGNIN, A. P.; LEMOS, B.; OLIVEIRA, S. B. Dinâmicas territoriais e políticas públicas na faixa de fronteira do Estado do Rio Grande do Sul. Revista Estudos de Planejamento, 2017, 7.

BELLINGIERI, J. C. Teoria do desenvolvimento regional e local: uma revisão bibliográfica. RDE-Revista de Desenvolvimento Econômico, v. 2, n. 37, 2017.

BOPPRÉ, N. F. Desenvolvimento: um novo foco para a região da Faixa de Fronteira Catarinense. In: CARIO, S. A. F. (org.) Características econômicas e sociais de Santa Catarina no limiar do século XXI. Criciúma, SC: UNESC, 2019, p. 262-284.

BOYER, R. Estado, mercado e desenvolvimento: uma nova síntese para o século XXI?. Economia e Sociedade, v. 8, n. 1, p. 1-20, 1999.

BRASIL. MINISTÉRIO DA INTEGRAÇÃO NACIONAL (MI). Proposta de reestruturação do Programa de Desenvolvimento da Faixa de Fronteira. Brasília: MI, 2005.

BRASIL. MINISTÉRIO DA INTEGRAÇÃO NACIONAL (MI). Secretaria de Programas Regionais. Faixa de fronteira: programa de promoção do desenvolvimento da faixa de fronteira-PDFF. 2009.

BRASIL. MINISTÉRIO DA INTEGRAÇÃO NACIONAL (MI). Portaria 125, de 21 de março de 2014. Republicada em 26 de março de 2014. Brasília, março de 2014. 
BRASIL. MINISTÉRIO DA INTEGRAÇÃO NACIONAL (MI). Portaria 213, de 19 de julho de 2016.

BRASIL. MINISTÉRIO DO DESENVOLVIMENTO REGIONAL. Relatório de atividades da Comissão Permanente para o Desenvolvimento e a Integração da Faixa de Fronteira 2019-2020 Brasília, 2020.

BRASIL. MINISTÉRIO DAS RELAÇÕES EXTERIORES. Disponível em https://www.gov.br/mre/pt-br/assuntos/mecanismos-internacionais/mecanismos-deintegracao-regional/mercosul. Acesso em 10 jun. 2021.

BRESSER-PEREIRA, L. C. Estratégia nacional e desenvolvimento. Revista de Economia Política, v. 26, n. 2, p. 203-230, abril-junho 2006.

CARGNIN, A. P. Política nacional de desenvolvimento regional e repercussões no Rio Grande do Sul. Revista Mercator, Fortaleza, v. 13, n. 1, p. 19-35, jan/abr. 2014.

DIAS, T.; CARIO, S. A. F. A gestão descentralizada adotada em Santa Catarina, o engajamento social e suas unidades regionais: de governo para governança no despontar do século 21 . Revista Catarinense de Economia, v. 1, n. 1, p. 183-210, 2017.

FALK, L. R. Políticas de fronteira no arco Sul do Brasil: desafios para a integração e o desenvolvimento regional. Encontro Estudantil Regional de Relações Internacionais, 2015.

FILIPPIM, E. S.; CETOLIN, S.F.; ISERN, P.; CASTRO, S. D. Cooperação transfronteiriça para o desenvolvimento regional. Desenvolvimento em Questão, 2014, 12.26: 5-40.

IGLESIAS, Enrique V. O papel do Estado e os paradigmas econômicos na América Latina. Revista de la CEPAL, 2010.

LIMA, A. C. C.; SIMÕES, R. F. Teorias clássicas do desenvolvimento regional e suas implicações de política econômica: o caso do Brasil. RDE-Revista de Desenvolvimento Econômico, v. 12, n. 21, 2010.

LINS, H. N. Cooperação transfronteiriça e desenvolvimento local no âmbito do Mercosul: uma experiência de consórcio intermunicipal. Análise Econômica, 2018, 36.70.

OLIVEIRA, G. B.; LIMA, J. E. S. "Elementos endógenos do desenvolvimento regional: considerações sobre o papel da sociedade local no processo de desenvolvimento sustentável." Revista da FAE 6.2 (2003).

PÊGO, B.; MOURA, R.; NUNES, M. KRÜGER, C; MOREIRA, P.; FERREIRA, G. (Orgs.). Fronteiras do Brasil: uma avaliação do arco Sul. Rio de Janeiro: Ipea; MDR, 2020. v. 5. Disponível em: https://www.ipea.gov.br/portal/index.php?option=com_content $\&$ view=article $\&$ id $=36432 \&$ cat id=435\&Itemid=448. Acesso em 11 jul. 2021

PÊGO, B.; MOURA, R.; NUNES, M.; KRÜGER, C.; NAGAMINE, L.; FERREIRA, G; MOREIRAR, P. (Orgs.). Fronteiras do Brasil: referências para a formulação de políticas públicas, volume 6 - Brasília: Ipea, MI, 2021. Disponível em: https://www.ipea.gov.br/portal/index.php?option=com_content\&view=article\&id=38053\&cat $\mathrm{id}=449 \&$ Itemid=457 Acesso em 11 jul. 2021.

SANCHEZ, F. M. Redes de governança: um estudo multicasos no setor público em Santa Catarina. Tese (Doutorado em Administração), Programa de Pós-Graduação em Administração. Universidade Federal de Santa Catarina, 2018. 
SERVIÇO BRASILERIO DE APOIO À MICRO E PEQUENAS EMPRESAS (SEBRAE/SC) Santa Catarina em números: Dionísio Cerqueira/Sebrae/SC. _ Florianópolis: Sebrae/SC, 2013. 132p.

VÁZQUEZ BARQUERO, A. Desenvolvimento endógeno em tempos de globalização. Fundação de Economia e Estatística, 2001. 